\title{
Ensino dos jogos esportivos na Educação Física escolar: o desenvolvimento da capacidade de jogo
}

\author{
Teaching of sportive games at physical education's school: steps to \\ improve the game capacity
} SILVA, S A. Ensino dos jogos esportivos na Educação Física escolar: o
desenvolvimento da capacidade de jogo. R. bras. Ci. e Mov 2015;23(1):95-102.
Siomara Aparecida Silva ${ }^{1}$

${ }^{1}$ Universidade Federal de Ouro Preto

RESUMO: Sistematizar os conteúdos da Educação Física na escola, contemplando os vários anos da educação básica de forma que o processo de ensino seja favorecido ainda é uma dificuldade para muitos professores. Desta maneira o objetivo deste estudo é conhecer a realidade da Educação Física escolar,e com base nesta planejar e executar atividades para o ensino dos esportes com o tema jogos esportivos, na busca da sistematização do processo de ensino da capacidade de jogo. Para tal, foram observadas aulas de Educação Física do ensino fundamental anos finais, de um professor em uma escola municipal da cidade de Ouro Preto-MG,durante o primeiro semestre letivo do ano de 2012. Após as observações registradas em um diário de campo foram realizados estudos teóricos no intuito de propor um planejamento para o ensino dos jogos esportivos coletivos que alcançasse uma possível sistematização. Através dos estudos foi escolhida a Metodologia da Iniciação Esportiva para a realização do planejamento das atividades que foram aplicadas durante o segundo semestre letivo do mesmo ano pelo pesquisador deste estudo. A execução das atividades planejadas foi registrada no diário de campo. Os resultados desta pesquisa indicam que o professor de Educação Física da escola ainda restringe os conteúdos da Educação Física aos jogos esportivos coletivos e não apresenta indícios de sistematização do mesmo. Existem subsídios teóricos que auxiliam o processo de ensino dos jogos esportivos, estes contribuem para que o planejamento alcance a sistematização dos mesmos. Consideramos que o profissional de Educação Física deve trabalhar de maneira planejada, orientada e sistematizada, mesmo que o seu principal conteúdo seja os jogos esportivos coletivos, pois, é possível aplicar a Metodologia da Iniciação Esportiva no contexto escolar, desenvolvendo a capacidade de jogo.

Palavras-chave: Escola; Sistematização de Ensino; Jogos Esportivos Coletivos; Metodologia da Iniciação Esportiva.

\begin{abstract}
To systematize the contents of Physical Education in school, taking into consideration the several years of basic education so that the educational process is favored is still a problem for many Professors. Thus the aim of this study is to know the reality of the school's Physical Education, and based on this, plan and execute activities to teach sports with the theme sports games, in the pursuit of the systematization of the process of teaching capacity of game. To this end, Physical Education classes from elementary to high school students of teacher at the school in Ouro Preto county were observed during the first semester of the school year of 2012. After the observations registered on a written field diary theoretical studies were performed in order to propose a schedule for the teaching of collective sports that could reach a possible systematic method. Through these studies it was chosen the Methodology of Sport Initiation to perform the planning activities that were implemented during the second semester of the same school year by the researcher of this research. This process was recorded on the field diary. The results of this research indicate that a PE teacher of school still restricts the contents of Physical Education to collective sports games and show no signs of its systematization. There are theoretical subsidies that help the process of systematization of the teaching of sport games, they contribute to the planning scope of systematization. We consider that the Physical Education professional must work on a planned, targeted and systematic way, even if your main content is the collective sports games and you can apply the Methodology of Sport Initiation in the school context, developing the ability to play.
\end{abstract}

Key Words: School; Systematization of Education; Sport Collective games; Methodology of Sport Initiation.
Recebido: $21 / 08 / 2014$

Aceito: 19/03/2015

Contato: Siomara Aparecida Silva - siomarasilva@cedufop.ufop.br 


\section{Introdução}

A práxis do professor no processo ensinoaprendizagem é a seleção, planejamento, sistematização e aplicação dos conteúdos nas aulas de Educação Física escolar,e esta pode ser traçada por dificuldades. Planejar de uma maneira sistêmica para os vários anos da educação básica, considerando os documentos norteadores da Educação Física, respeitando a cultura e principalmente o aprendiz, é o que compõe a dificuldade. Mas vencer esta dificuldade torna o processo facilitador para o aprendizado.

Os documentos norteadores influenciam diretamente o plano e o programa de ensino do professor, que depende hierarquicamente dos pilares do projeto pedagógico da escola sustentado pelas diretrizes do estado e da nação. Existem críticas a essas diretrizes,como: elas não possibilitam uma aproximação entre as diversas tendências da Educação Física e que estas aprofundam somente em uma perspectiva fazendo com que a proposta de intervenção seja precária ${ }^{1}$.

Independente das críticas, as diretrizes orientam o planejamento do professor, e este é resultado também da sua formação, ideologia e experiência. Um dos elementos que compõe a atuação profissional são as experiências anteriores dos sujeitos quando atleta e enquanto aluno, o que significa que o professor pode levar para a prática as experiências vividas e aprendidas na escola, no processo de treinamento e na graduação ${ }^{2}$.

Estas experiências variam entre os professores e são levadas para a prática na Educação Física escolar, na busca pelo desenvolvimento de diferentes alcances da prática esportiva como o da saúde, o alto nível de rendimento, a educação, o social e até mesmo o profissional (desenvolver o gosto do aluno pela profissão).

Nesta busca, os professores costumam escolher, dentre as tendências ou abordagens existentes da Educação Física, a que se adéqua ao seu objetivo. As tendências ou abordagens surgiram com o objetivo de romper com o modelo mecanicista vigente por muito tempo na Educação Física ${ }^{3}$ sendo opção para o professor e o processo de ensino.
A falta de convergência presente nas diretrizes para o desenvolvimento dos diferentes alcances pode ser outro fator que dificulta o processo de sistematização de ensino. $\mathrm{Na}$ escola,muitos dos professores, ainda influenciados por uma concepção esportivista, além de restringir os conteúdos das aulas aos esportes mais tradicionais (basquetebol, voleibol e futebol) costumam distribuí-los sem nenhuma sistematização e apresentá-los aleatoriamente, sem nenhum critério. É possível perceber que as modalidades que os alunos mais gostam sejam abordadas nas aulas de Educação Física são basquetebol, futebol, voleibol e handebol ${ }^{4,5}$.

Isso significa que os jogos esportivos fazem parte da cultura brasileira representada na escola e que proporciona prazer aos seus praticantes. Os mesmos estão contidos nos documentos norteadores como parte do conteúdo esporte e existe a possibilidade de desenvolver os diferentes alcances da prática esportiva,quando se ensina para além do esporte.

A falta de teorias dos jogos esportivos, direcionadas a seriação comum nas escolas e o predomínio influente das metodologias formais, do ensino da técnica,e de uma ausência de organização de conteúdos que constroem, principalmente, para o ensino do esporte através do jogo contribuem para a falta de sistematização.

Pinheiro ${ }^{4}$, ressalta que não se pode negar que o conteúdo esportes e apresenta na escola com relevância para os alunos, os esportes tradicionais são importantes conteúdos da Educação Física e sua aplicação não deve ser negada em se tratando de conhecimento de uma cultura,deve ser sistematizada, para que não favoreça a sua negação no âmbito escolar, através da vivência, do conhecimento, da análise crítica e reflexiva sobre a sua construção social ${ }^{6}$.

Para o ensino dos jogos esportivos Reverdito e Scaglia ${ }^{7}$ afirmam que existe um conjunto de autores que tem se dedicado à missão de sustentar uma abordagem pedagógica condizente e capaz de atender as necessidades atuais do ser humano,estas apresentam caracterização, estratégia-metodologia e fundamentação. 
De acordo com as diferentes estratégias e metodologias percebe-se que o ensino dos esportes deve acontecer através da construção da capacidade de jogo (com a transferência de aprendizagem e variação no ensino das habilidades), orientado de forma incidental (de acordo com as situações de jogo).

Partindo dessas condições o que falta a ser definido é o planejamento prático de quando e por quanto tempo deve acontecer o processo de ensino. Este planejamento prático pode ser vislumbrado com um processo de sistematização de longo prazo, que consiste em organizar os conteúdos da Educação Física escolar de modo coerente com cada nível (anos, anteriormente séries) de ensino ${ }^{8}$.

A Iniciação Esportiva Universal (IEU) de Greco e Benda $^{9}$ é uma das abordagens citadas por Reverdito e Scaglia $^{7}$ que se apoia nos alcances do desenvolvimento motor para organizar ao longo dos anos, conteúdos direcionados às características de cada faixa etária.

Possivelmente desta maneira o planejamento estaria ancorado em um processo de sistematização a longo prazo. A crítica feita às novas abordagens pedagógicas, em especial a IEU, se deve à falta de comprovações práticas das mesmas ${ }^{10}$.

Desta maneira o objetivo deste estudo é conhecer a essência da realidade da educação física escolar e, com base nesta planejar e executar atividades para o ensino dos esportes com o tema jogos esportivos,na busca da sistematização do processo de ensino.

\section{Materiais e Métodos}

Para nos aproximar dos objetivos desta pesquisa descreveremos a primeira etapa das observações, e no segundo momento, pesquisa ação, o pesquisador atuou como professor na execução das atividades planejadas. As observações foram descritas no diário de campo ao longo das aulas nos dois momentos.

A pesquisa aconteceu durante um ano em uma escola da rede pública da cidade de Ouro Preto-MG. Foram acompanhadas as aulas de duas turmas dos anos finais do ensino fundamental $\left(6^{\circ}\right.$ e $7^{\circ}$ anos). Em cada turma, após as observações, foram realizadas 18 aulas do conteúdo esportes, com o tema jogos esportivos, um total de36 aulas para as duas. No primeiro semestre foram observadas as aulas do professor da escola e no segundo semestre aconteceram as aulas do professor pesquisador.

A pesquisa foi dividida em três partes: a primeira de observação (das aulas do professor efetivo da escola), a segunda de estudos teóricos e planejamento de intervenção (durante o período de férias escolares) e a terceira de intervenção, esta aconteceu após o consentimento e aprovação do professor.

Além da aprovação do professor, todos os alunos assinaram o termo de consentimento livre esclarecido para participar da pesquisa, que aconteceu durante o ano de 2012, e estes procedimentos tiveram aprovação do comitê de ética em pesquisa da Universidade Federal de Ouro Preto (CAAE: 0049.0.238.00-11).

\section{Resultados}

Aulas do Professor da Escola

No início do estudo foram solicitados ao professor os seus planos de aula, na tentativa de saber qual tendência/abordagem o mesmo adotava, porém não conseguimos o acesso a estes documentos. Diante das observações somente não foi possível identificar critério de planejamento dos conteúdos por parte do professor, pois não se observa uma sequência pedagógica e metodológica.

Nas 36 aulas os conteúdos observados foram: 14 de futsal, 10 de atletismo, quatro de filme, quatro de avaliações, duas de basquetebol e duas aulas de queimada. Os jogos esportivos representam $44,44 \%$ das aulas quando agrupados e o atletismo $27,77 \%$, o restante se refere às avaliações e aulas com filme. Na aula livre proposta pelo professor a escolha do que fazer era feita pelos alunos, sem restrição ou intervenção do mesmo durante a aula.

Como a maioria das aulas de esportes era considerada livre (no qual os alunos escolhiam o conteúdo), não foi possível observar sistematização na sequência dos conteúdos de jogos desportivos apresentados e adequação dos mesmos às diferentes 
faixas etárias (os conteúdos foram desenvolvidos da mesma maneira para as duas turmas).

O quadro abaixo apresenta a relação de conteúdos desenvolvidos na sequência pelo professor, observados e relatados no diário de campo durante o primeiro semestre e a observação das 36 aulas.

\begin{tabular}{|c|c|c|}
\hline Aulas & $6^{\circ}$ ano & $7^{\circ}$ ano \\
\hline $\mathrm{Um}$ & Atletismo & Atletismo \\
\hline Dois & Filme & Filme \\
\hline Três & Atletismo & $\begin{array}{c}\text { Aula livre: } \\
\text { Futsal }\end{array}$ \\
\hline Quatro & $\begin{array}{c}\text { Aula livre: } \\
\text { Basquetebol }\end{array}$ & Filme \\
\hline Cinco & $\begin{array}{l}\text { Aula livre: } \\
\text { Queimada }\end{array}$ & $\begin{array}{c}\text { Aula livre: } \\
\text { Futsal }\end{array}$ \\
\hline Seis & $\begin{array}{c}\text { Aula livre: } \\
\text { Futsal }\end{array}$ & Filme \\
\hline Sete & $\begin{array}{c}\text { Aula livre: } \\
\text { Futsal }\end{array}$ & $\begin{array}{c}\text { Aula livre: } \\
\text { Futsal }\end{array}$ \\
\hline Oito & Atletismo & Filme \\
\hline Nove & $\begin{array}{l}\text { Aula livre: } \\
\text { Basquetebol }\end{array}$ & Atletismo \\
\hline Dez & Avaliação & Avaliação \\
\hline Onze & Atletismo & $\begin{array}{c}\text { Aula livre: } \\
\text { Futsal }\end{array}$ \\
\hline Doze & Avaliação & $\begin{array}{l}\text { Aula } \\
\text { teórica }\end{array}$ \\
\hline Treze & $\begin{array}{l}\text { Aula livre: } \\
\text { Futsal }\end{array}$ & $\begin{array}{c}\text { Aula livre: } \\
\text { Futsal }\end{array}$ \\
\hline Quatorze & $\begin{array}{l}\text { Aula livre: } \\
\text { Queimada }\end{array}$ & $\begin{array}{c}\text { Aula livre: } \\
\text { Futsal }\end{array}$ \\
\hline Quinze & $\begin{array}{l}\text { Aula livre: } \\
\text { Futsal }\end{array}$ & $\begin{array}{c}\text { Aula livre: } \\
\text { Futsal }\end{array}$ \\
\hline Dezesseis & $\begin{array}{l}\text { Aula livre: } \\
\text { Futsal }\end{array}$ & Atletismo \\
\hline Dezessete & Atletismo & Atletismo \\
\hline Dezoito & $\begin{array}{l}\text { Aula livre: } \\
\text { Futsal }\end{array}$ & $\begin{array}{c}\text { Aula livre: } \\
\text { Futsal }\end{array}$ \\
\hline
\end{tabular}

Quadro 1. Aulas realizadas na sequência pelo professor da escola

\section{Planejamento de Intervenção}

Para o planejamento foram estudadas as abordagens pedagógicas citadas por Reverdito e Scaglia ${ }^{7}$, dentre elas foi escolhida para a sistematização de ensino dos esportes a metodologia da iniciação esportiva ${ }^{9}$.

Nesta metodologia se ensina o esporte pelo esporte e desta maneira acredita-se na possibilidade de proporcionar oportunidades para os diferentes níveis de rendimento (saúde, alto nível, educação, social e profissional). Quando se ensina o esporte, ensina-se também pelo esporte como meio para o desenvolvimento de competências, comportamentos, atitudes e valores ${ }^{11}$.

Esta metodologia é sustentada pela proposta desenvolvimentista, isso faz com que o planejamento respeite as características dos alunos e possa mudar de acordo com as faixas etárias e com os anos de escolaridade, o que constitui a estrutura temporal da proposta.

Com base nas características do desenvolvimento a metodologia define o que deve ser trabalhado em cada faixa etária para o ensino dos jogos esportivos (estas informações estão contidas na estrutura substantiva) com os parâmetros de cada um de seus conteúdos: da aprendizagem motora e da aprendizagem tática construindo a capacidade de jogo.

Através da forma de ensino incidental e do método situacional acredita-se que os alunos são favorecidos no desenvolvimento da inteligência e criatividade tática, gerando consequências na melhoria da tomada de decisão que se aproxime das situações reais de jogo.

A variabilidade de atividades que se alcança com esta metodologia, por apresentar parâmetros de ensino (que auxiliam na construção da capacidade de jogo),ajudam o professor a criar atividades diferentes e contribui para que as aulas não se tornem repetitivas e cansativas.

Esta metodologia com as suas estruturas (temporal, metodológica e substantiva) sustenta o Sistema de Aprendizagem e Desenvolvimento Esportivo (SADE) que é uma concepção pedagógica de ensino-aprendizado dos esportes, relacionada aos processos de desenvolvimento 
motor, que respeita as características do desenvolvimento humano, e a realidade do Brasil ${ }^{12}$.

O SADE pode ser entendido como um sistema de treinamento a longo prazo que pode servir de subsídio teórico para a sistematização de uma proposta de trabalho para as práticas esportivas escolares ${ }^{13}$.

O ponto negativo de se utilizar esta metodologia é a necessidade de muitos e diferentes materiais, o que para a execução das atividades variadas torna-se um problema em muitas escolas, que pode ser resolvido com materiais alternativos. Para a aplicação das aulas os materiais utilizados neste estudo pertenciam ao Laboratório de Metodologia de Ensino dos Esportes (LAMEES).

No planejamento, procurou-se respeitar a faixa etária e o ano das turmas (entre 11 e 14 anos $/ 6^{\circ}$ e $7^{\circ}$ anos) de acordo com a estrutura temporal, método situacional de acordo com a estrutura metodológica e o desenvolvimento dos parâmetros dos conteúdos da aprendizagem motora (responsável por desenvolver a coordenação motora e habilidades técnicas) e a aprendizagem tática (com as capacidades táticas básicas, jogos para o desenvolvimento da inteligência e criatividade e estruturas funcionais) de acordo com a estrutura substantiva.

\section{Aplicação do Planejamento de Intervenção}

O tempo de cada aula era de 50 minutos, no entanto, o tempo médio de prática era de somente 40 minutos, 10 minutos da aula eram despendidos com a locomoção para a quadra e o retorno dela, a "chamada", as explicações e discussões dos conteúdos da aula.

A aula era dividida em três partes (inicial, principal e final). Na parte inicial era realizada uma conversa com os alunos reunidos no centro da quadra abordando o conteúdo e os objetivos da aula do dia. $\mathrm{Na}$ parte principal foram desenvolvidas as atividades abordando os conteúdos da aprendizagem motora e aprendizagem tática no ensino dos jogos desportivos.

$\mathrm{Na}$ parte principal foram desenvolvidas atividades que haviam sido planejadas com base à proposta escolhida para a sistematização. $\mathrm{Na}$ parte final era realizada uma avaliação da aula, juntamente com os alunos, através de perguntas sobre as atividades realizadas e se os alunos gostaram ou não da aula do dia.

Os conteúdos foram desenvolvidos no contexto dos jogos esportivos sistematizados em habilidades com as mãos (lançamento, drible e rebatidas) e habilidades com os pés (chute e condução).

Como resultado do planejamento os conteúdos foram distribuídos em Capacidades Táticas Básicas (CTB) presente em $86 \%$ das aulas, Jogos para o Desenvolvimento da Inteligência e Criatividade (JDIC) 30,5\%, Habilidades Técnicas (HT) 41,6\% e Coordenação Motora (CM) 86\%. Os parâmetros das estruturas funcionais não foram desenvolvidos devido a idade dos alunos, ambiente escolar (que não objetiva especificidade) e o espaço/materiais disponíveis para aplicação da proposta.

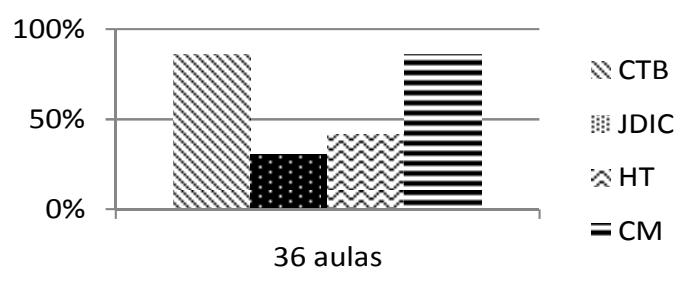

Figura 1. Conteúdos desenvolvidos nas aulas sistematizadas

Os jogos para o desenvolvimento da inteligência e criatividade foram trabalhados na quadra e em sala de aula com jogos (da velha, de damas, de xadrez) e a análise processual de situação de jogo com o objetivo de desenvolver atenção, percepção e tomada de decisão.

No geral com relação à participação dos alunos nas aulas de Educação Física foram encontradas algumas dificuldades no início para a realização das atividades propostas, houve dificuldade de controlar e incentivar os alunos a fazerem as aulas, pois os mesmos queriam jogar o jogo formal, especificamente o futsal.

Além da dificuldade de quebrar esse paradigma do jogo de futsal predominante nas aulas de Educação Física (percebido principalmente na turma dos alunos mais velhos) outros fatores relatados pelos alunos que afetam a participação nas aulas de Educação Física são: falta de 
interesse, timidez, medo de errar e não gostar de determinadas atividades propostas.

Nas intervenções não ocorreu situação de evasão de alunos nas aulas, sendo que todos os alunos procuraram participar destas. Na execução das atividades os limites dos alunos foram respeitados, na tentativa de melhorar o nível motor e aprimorando as habilidades.

No final das intervenções foi realizada uma avaliação, com os alunos, para identificar os pontos positivos e negativos. No geral os alunos acharam as aulas interessantes e divertidas, porém reclamavam do grande número de alunos jogando ao mesmo tempo.

As meninas relataram gostar, pois geralmente as aulas de Educação Física eram somente o jogo de futsal e elas não gostam de jogar, preferiam ficar sentadas conversando. O que chama atenção é a fala de algumas meninas dizendo que gostaram das aulas, pois todos podiam jogar e ninguém ficava sem fazer nada. Os meninos gostaram e acharam as atividades legais e divertidas, porém a preferência ainda era "bater o ranca" (como se fala na região) que significa jogar o jogo formal de futsal.

\section{Discussão}

O conteúdo mais desenvolvido pelo professor durante o período de observação foram os esportes, com predominância nos Jogos Desportivos. O quadro de observações indica que ocorreu uma esportivização das aulas de Educação Física durante o período de observação.

Em um estudo autores $^{14}$ identificaram que a Educação Física escolar tende a apresentar uma esportivização de seus conteúdos em algumas séries do ensino fundamental. Esta pesquisa constitui-se em observações de aulas de turmas de sétima e oitava séries do ensino fundamental, que verificou que $54,1 \%$ das aulas observadas apresentaram conteúdo esportivo tradicional o que corrobora com nossos achados.

Outro estudo que apoia estes achados é o de Pereira e Silva ${ }^{15}$, realizado em escolas do RS das redes federal, estadual e privada. Através de análises documentais e entrevistas com 22 professores de 18 instituições, em seis diferentes cidades, em aulas para o ensino médio, dentre os conteúdos, os esportivos compreenderam $66,9 \%$ contribuindo para a supremacia e hegemonia do esporte dentro do contexto escolar.

Um estudo sobre a sistematização dos conteúdos da Educação Física na escola foi possível identificar que os professores de Educação Física têm restringido seu trabalho aos esportes tradicionais, que são transmitidos superficialmente, e em geral distribuídos sem nenhuma sistematização ${ }^{4}$.

Quando a fazem, os professores dispõem os conteúdos ao longo do ano através dos bimestres, com um esporte coletivo como conteúdo principal, e outros conteúdos dispostos paralelamente durante o ano, no caso, os jogos e outros esportes, mas não há mudanças ao longo do ciclo de escolaridade.

Outro estudo realizado indica que grande parte dos professores tem dificuldade para pensar a organização dos conteúdos ao longo dos anos escolares, e esta situação induz os docentes a elaborar por si próprios a sistematização dos conteúdos, o que pode ser explicação para os resultados encontrados ${ }^{16}$.

De acordo com Correia ${ }^{17}$ os documentos norteadores denominados por ele como "proposições", não alcançaram uma consistência sistematizadora e seria preciso efetuar uma imersão dentro dos muros da escola, pois é lá que se quer atuar.

Poucos estudos foram realizados utilizando a metodologia da Iniciação Esportiva Universal. Um estudo que apresenta objetivo diferente deste, porém é realizado com alunos da mesma faixa etária (11 a 14 anos), e que utiliza da aplicação da mesma proposta metodológica, evidenciou um aumento do repertório de soluções táticas ante a imprevisibilidade inerente aos jogos desportivos, mesmo não sendo o foco deste estudo, estas informações contribuem para a explicação dos motivos pelo qual se escolheu esta proposta ${ }^{11}$.

\section{Conclusão}

O profissional de Educação Física deve trabalhar de maneira planejada, orientada e sistematizada, mesmo que o seu principal conteúdo seja somente os esportes (em 
101 Capacidade de jogo no ensino dos esportes na escola especial os jogos esportivos). É possível aplicar a proposta da Metodologia da Iniciação Esportiva no contexto escolar,o ponto negativo desta é que algumas escolas podem não apresentar a quantidade suficiente de materiais, porém a utilização de materiais alternativos pode ser uma opção para solucionar este problema.

\section{Agradecimentos}

A FAPEMIG pelo apoio financeiro concedido através da bolsa de Iniciação Científica. Aos membros do Laboratório de Metodologia de Ensino dos Esportes LAMEES e ao Grupo de Estudos das Capacidades de Rendimento dos Esportes Coletivos - GECREC pelas contribuições. 


\section{Referências}

1 Sanches Neto, L.; Betti, M. Convergência e integração: uma proposta para a educação física de $5^{\mathrm{a}}$ a $8^{\mathrm{a}}$ série do ensino fundamental. Revista Brasileira de Educação Física e Esporte. São Paulo. 22: 5-23 p. 2008.

2 Darido, S. C. Teoria, prática e reflexão na formação profissional em educação física. MOTRIZ. V Simpósio Paulista de Educação Física. 11995.

3 Bento, L. C. M.; Ribeiro, R. D. As aulas de educação física na concepção dos alunos de $5^{\mathrm{a}}$ a $8^{\mathrm{a}}$ series do ensino fundamental da cidade de Indianópolis-MG. Motrivivência: 354-368 p. 2008.

4 Rosário, L. F. R.; Darido, S. C. A sistematização dos conteúdos da educação Física na escola: a perspectivas dos professores experientes. Motriz. Rio Claro. 112005.

5 Pinheiro, M. C. et al. Outra Vez, Professor? percepções de alunos em relação à educação física. Motrivivência. 25: 90-105 p. 2013.

6 Silva, J. V. P. D. Prática pedagógica em educação física nos anos iniciais do ensino fundamental. Pensar a Prática: Goiânia. 16: 1-319 p. 2013.

7 Reverdito, R. S.; Scaglia, A. J. Pedagogia do esporte: Jogos coletivos de invasão. São Paulo: 2009.

8 Kawashima, L. B.; Souza, L. B.; Ferreira, L. A. Sistematização de conteúdos da educação física para as séries iniciais. Motriz. Rio Claro. 15: 458-468 p. 2009.

9 Greco, P. J.; Benda, R. N. Iniciação Esportiva Universal. Da aprendizagem motora ao treinamento técnico. Belo Horizonte: Ed. UFMG, 1998.

10 Tani, G.; Basso, L.; Corrêa, U. C. O ensino dos esportes para crianças e jovens: considerações sobre uma fase do processo de desenvolvimento motor esquecida. Revista brasileira educação física e esporte. São Paulo. $26: 339$ p. 2012.

11 Ricci, G. S. et al. Avaliação da aprendizagem do handebol por jovens entre 11 e 14 anos a partir do método situacional. Pensar a Prática. Goiânia. 14: 1-18 p. 2011.

12 Greco, P. J.; Silva, S. A.; Santos, L. R. Organização e Desenvolvimento Pedagógico do Esporte no Programa Segundo Tempo. In: Oliveira, A. A. B. e Perim, G. L. (Ed.). Fundamentos pedagógicos do programa segundo tempo: da reflexão a prática. Maringá: Eduem, 2009. p.163-206.

13 Böhme, M. T. S. Esporte infanto-juvenil:treinamento a longo prazo e talento esportivo. São Paulo: 2011.

14 Gueriero, D. A.; Araújo, P. F. Educação Física Escolar ou Esportivização Escolar? EFD esportes. Buenos Aires. 102004.

15 Pereira, F. M.; Silva, A. C. Sobre os conteúdos da Educação física no ensino médio em diferentes redes educacionais no Rio Grande do Sul. Revista da Educação Física / UEM. Maringá. 152004.

16 Impolcetto, F. M.; Darido, S. C. Sistematização dos conteúdos do voleibol: possibilidades para a educação física escolar. Revista Brasileira Ciência e Movimento. 19: 90-100 p. 2011.

17 Correia, W. R. Educação Fisica escolar: entre inquietudes e impertinencias. Revista Brasileira de Educação Física e Esporte: São Paulo. 26: 171-178 p. 2012. 